\title{
LOS TÉRMINOS COMPLEMENTARIOS EN LA TRADUCCIÓN AL ESPAÑOL DE TEXTOS PERIODÍSTICOS ALEMANES: LITERALIDAD ESPECÍFICA O RECURSO ESTILÍSTICO
}

\section{Carmen Castro Moreno}

\begin{abstract}
This article pretends to show how complementary terms and their repetition help in the text translation. We specially consider the theory of communicationfocusing the contrast between the german and spanish language. We also create a methodologic application that includes some glosaries and newspaper examples in order to simplify our explanations.
\end{abstract}

\section{LOS TÉRMINOS COMPLEMENTARIOS Y SU TRADUCCIÓN}

Si consideramos la terminología especifica que presentan los textos periodísticos, nos llama la particular atención el léxico reiterativo que éstos presentan. Esta terminología o léxico específico cobra su importancia a la hora de su traducción. En el caso que nos atañe, el de la traducción del alemán al español vs. español al alemán somos conscientes de una lexicalidad complementaria entre ambas lenguas, que bien unas veces se adecua o transfiere íntegramente y, otras veces, presenta una dificultad intrínseca debido a la divergencia entre los sistemas alemán y español a nivel morfoestructural. En lo siguiente trataremos de dilucidar cuál es el léxico específico al que nos referimos y qué implicaciones trae consigo desde su perspectiva traductológica.

Traducir consiste en expresar en una lengua y por escrito lo que se ha expresado en otra lengua. La lengua a la que se transfiere se denomina lengua terminal (LT) y la lengua de la que se parte es conocida como lengua original (LO). No obstante, y como quiera que lo que se traduce no son lenguas sino textos, se puede precisar más exactamente el concepto de traducción y afirmar que ésta consiste en el paso de un texto de la lengua original (TLO) a un texto de la lengua terminal (TLT). Es decir, traducir es sustituir un TLO por un TLT equivalente ${ }^{1}$.

\footnotetext{
${ }^{1}$ La traducción es un acto complejo de comunicación en el que intervienen, además del texto de la lengua original, la interpretación de ese texto por parte del traductor, el texto de la lengua terminal y el receptor. La importancia del receptor en el proceso de la traducción es esencial. Para traducir no es suficiente el conocimiento de las lenguas. Tan importante o más es la consideración de las circunstancias culturales, históricas y sociológicas de los receptores a los que va dirigida la traducción. La función de la traducción, por tanto, esto es, la cuestión de para quién o para qué se traduce, es un factor determinante del proceso traslativo que debe de guiar la estrategia de traducción. El traductor procurará, en lo fundamental, que el texto adecuado transmita el mismo contenido comunicativo a sus receptores que el texto original. Lo decisivo en traducción, por tanto, no es la equivalencia formal sino la equivalencia funcional o comunicativa, es decir, no el significado literal sino la equivalencia dinámica. Lo importante es el contenido del mensaje; de manera que el traductor tendrá que realizar los cambios formales necesarios para reproducir y conservar el contenido. Así estaría justificada la introducción de cambios en el texto al objeto de obtener una respuesta semejante en los receptores del texto terminal.
} 


\section{ANÁLISIS TEORICO-PRÁCTICO DE TEXTOS PERIODÍSTICOS}

A. Neubert (1995) y S. Lambert (1999) definen el texto periodístico como un tipo de escrito en el que la función predominante de la lengua es la representativa ${ }^{2}$. Este tipo de texto nos hace partícipes o nos transmite un contenido básicamente informativo ${ }^{3}$.

\section{1. Análisis de la forma}

Para W. Koller (1983) la clasificación más acertada de textos periodísticos viene dada por la fundamentación en seis apartados: noticias, crónicas, reportajes, entrevistas, documentación y artículos de opinión y análisis. Por su parte H. D. Kübler (1994) argumenta que la noticia trata de comunicar acontecimientos o ideas a un público heterogéneo con claridad, concisión y adaptación a la comprensibilidad ${ }^{4}$. L. D. Wright y S. E. Wright (2003) en "Scientific and technical translation", aclaran a su vez que la noticia comienza con el hecho más destacado y en su desarrollo funcional se analizan detalles e informaciones adicionales de los acontecimientos secundarios.

\subsubsection{El texto periodístico}

Grosso modo destacamos que la noticia se compone de las siguientes partes:

1) Titulares: Constituyen el elemento principal de una noticia. Centran la atención del lector y deben ofrecer lo más importante de una información. Han de ser inequivocos y concretos. Se componen del cintillo, el antetitulo, el título, el subtítulo y el sumario 5 .

2) Entradilla: Es el primer párrafo. Aquí se da respuesta a las cuestiones de quién, qué, cómo dónde, cuándo y por qué.

3) Cuerpo informativo: En esta parte se desarrolla la información. Aquí se aportan nuevos datos, se explican los antecedentes y se indican las consecuencias. No debe incluir opiniones particulares o juicios de valor del traductor.

\subsubsection{La traducción del texto periodístico}

El proceso traslativo del texto peridístico se desarrolla en diferentes fases, que se pueden reducir fundamentalmente a dos: una fase de comprensión en la que el traductor analiza los componentes del texto en TLO en sus diferentes niveles (pragmático, semántico y morfosintáctico); y una fase de reverbalización en la que el traductor intenta 'reproducir'

\footnotetext{
${ }^{2}$ En Text and translation y The cloze technique as a pedagogical tool for the training of translators and interpreters respectivamente.

${ }^{3}$ A partir de este ap. II analizaremos la forma y contenido teórico-pragmático de textos periodísticos.

${ }^{4}$ En Kommunikation und Massenkommunikation.

${ }^{5}$ - Cintillo: Agrupa dos o más noticias relacionadas entre si. Se sitúa por encima del antetítulo. - Título: Es la parte principal de un titular y la única de la que no sepuede prescindir. Debe contener lo más importante de la noticia. El título suele ser breve, afirmativo, de sintaxis sencilla y aparecer en un tiempo verbal en presente. En su formulación se evitan las expresiones de probabilidad, los signos de puntuación, la letra cursiva (se sustituye por comillas simples) y la primera frase del texto. - Antetitulo, subtítulo y sumario: Complementan el titulo. Explican o desarrollan la noticia y resaltan parte del texto.
} 
en el TLT las características de sentido y estilo del TLO, teniendo en cuenta una equivalencia comunicativa óptima ${ }^{6}$.

La primera y fundamental actividad del traductor en el proceso traslativo es la comprensión del texto de partida, sin la cual es imposible realizar la traducción. En el texto de partida concurren factores internos y factores externos, que deberán ser considerados en su conjunto, globalidad e interrelación. Los factores internos atañen a la estructura lingüística del texto en los niveles morfosintáctico y léxico-semántico, así como a su contenido, temática y características formales no verbales (fotos, dibujos, esquemas, tipo de impresión, etc.) y suprasegmentales. Los factores externos se refieren al emisor y su intención, receptor, medio o canal, función del texto, lugar y tiempo, realidad extralingüistica y situación comunicativa. La fase de comprensión deberá considerar, por consiguiente, los siguientes factores: I. SITUACIÓN 1. Emisor 2. Intención 3. Receptor 4. Lugar 5. Tiempo 6. Motivo 7. Medio 8. Función textual II. CONTENIDO 1. Tema 2. Estructura III. FORMA 1. Diseño 2. Tipo IV. ESTILO 1. Morfosintaxis 2. Léxico.

\subsubsection{Metodología}

La metodología a aplicar en la traducción del texto periodístico se fundamentará inicialmente en un análisis del texto de partida ${ }^{7}$. Continuará una fase de conocimiento profundo de textos similares y complementarios en alemán y de textos paralelos en español ${ }^{8}$. Seguirá, finalmente, la producción del texto en la lengua de llegada, o sea, la traducción.

\section{Primera fase: Fase de comprensión ${ }^{9}$}

En el ámbito cultural se prestará atención especialmente al tratamiento de instituciones, partidos políticos, nombres y personajes. En el aspecto lingüístico deberán considerarse sobre todo los grupos nominales, las oraciones de participio, las oraciones subordinadas y las construcciones pasivas (Crf. R. Arntz / G. Thome, 1990; J. Albrecht, 1993; M. Ballard, 1996; J. Del Río Reynaga, 2001).

\footnotetext{
${ }^{6}$ De aquí se desprende que el traductor es el factor esencial del proceso traslativo, de cuya competencia depende en gran medida el éxito o el fracaso de la operación de traducción. El traductor actúa en primer lugar como receptor del TLO, para convertirse a continuación en 'emisor' al producir un texto en la LT. Su competencia traslativa es el resultado de diversas subcompetencias: competencia receptiva en la LO, competencia productiva en la LT, conocimiento de la realidad extralingüística o sociocultural de la comunidad de la LO y de la LT, y competencia de traducir o trasladar de una lengua a otra.

${ }^{7}$ Esta metodologia ha de facilitar su compresión y ha de permitir determinar los problemas que presenta su traducción.

${ }^{8}$ Esta segunda fase implica una rigurosa labor preparatoria y de documentación, que posibilite encontrar soluciones a los problemas de traducción planteados.

${ }^{9}$ Esta fase se iniciará con un análisis del texto en lengua original en los niveles pragmático, semántico y morfosintáctico, que permita su cabal comprensión. Ya en este primer acercamiento al texto original se determinarán los problemas que presenta su traducción. Estos problemas pueden ser de indole cultural y lingüistica.
} 


\section{Segunda fase: Fase de preparación}

En esta segunda fase de preparación de la traducción se realizará una amplia labor de documentación. En lo fundamental, se usarán diccionarios monolingües y bilingües y se consultarán y leerán textos similares, complementarios y paralelos ${ }^{10}$. Los textos similares y complementarios ofrecen una mayor información sobre el tema del texto a traducir. Los textos paralelos, por su parte, ofrecen posiblessoluciones a los problemas surgidos en el análisis del texto original; permiten la adquisición y consolidación de conceptos temáticos, terminología, estructuras sintácticas y convenciones propias del texto periodístico en la lengua materna. Se prestará especial atención a los siguientes aspectos propios de los textos periodísticos españoles (Cfr. J. Delisle, 1993; J. Gutiérrez Palacio, 1994; J. F. Fuentes / J. Fernández Sebastián, 1997; C. Dollerup y A. Lindegaard, 2004; J.C. Catford, 2005) ${ }^{11}$.

\section{Tercera fase: Fase de traducción}

En esta última fase se traducirá el texto de partida. Se realizará una primera versión que será posteriormente revisada y corregida (Cfr. K. Kosyk / K. H. Pruys, 1981; P. Elena Garcia 1994; A. Hurtado, 1995: 6, H. G. Hönig, 1997).

\section{2. Análisis de contenidos: el mensaje y la información periodística}

La información periodística es un fenómeno de comunicación entre determinados grupos humanos. Como todo acto comunicativo, participa de elementos como el emisor (el periodista), el receptor (el lector, televidente, internauta o radioyente), el mensaje (la noticia), el código (lenguaje periodístico) y los medios o canales de transmisión (periódico, radio, televisión, internet). Miguel Urabayen (1998: 13-14) define así el concepto de información periodística: Información Periodística es la referente a noticias, datos y opiniones, publicadas en forma regular por medio de palabras e imágenes, con el fin básico de satisfacer el deseo de conocimiento de la actualidad en quien recibe tal información.

\subsubsection{El lenguaje periodístico}

Mensaje es todo aquello que deseamos comunicar, transmitir, expresar, decir, escribir, etc. Todo mensaje se transmite por un medio determinado -aire, libro,red, teléfono, ondas, etc. Si aplicamos esta misma definición al mensaje periodístico, podemos afirmar que es la información periodística que se quiere transferir a receptores hetereogéneos, mediante el

\footnotetext{
${ }^{10}$ Textos similares: son textos escritos en la misma lengua original, pertenecientes a la misma clase, pero publicados en medios de comunicación distintos. Textos complementarios: son textos escritos en la misma lengua original, sobre el mismo tema, pero de clase diferente. Textos paralelos: son textos escritos en la lengua terminal, de la misma clase y sobre el mismo tema.

II - Titulares (en alemán son más telegráficos; en español son más completos, incluyen artículos, pronombres posesivos, etc.) • Empleo de las letras mayúsculas y minúsculas - Signos de puntuación - Uso de la cursiva y la negrita - Tratamiento de partidos políticos, instituciones, nombres y personajes - Indicación de las fuentes $\cdot$ Nombres de ciudades, regiones y paises - Gentilicios - Siglas - Alternancia estilo directo - estilo indirecto • Conectores - Tiempos verbales • Estructuras sintácticas (estructuras hipotácticas y paratácticas, construcciones de infinitivo).
} 
acto comunicativo (Cfr. I. Van Dam, 1989; P. San Ginás Aguilar, 1990; T. Sáez Hermosilla, 1994; R. Stolze, 1997; Moreno Espinosa, 1998: 43; M. Snell-Hornby, 1998) ${ }^{12}$.

El lenguaje periodístico, aunque con caracteristicas particulares y propias, ha de ser un lenguaje correcto, lo cual implica el conocimiento de la Gramática y de la Lingüística. El periodista ha de conocer, además del uso correcto del lenguaje, aquellas reglas específicas que constituyen el denominado lenguaje periodístico. Estas reglas afectan, según G. Martín Vivaldi (2003: 10), a la expresión escrita, gráfica, oral, icónica y audiovisual de los distintos soportes tecnológicos mediante los cuales se transmite la información periodistica ${ }^{13}$.

\subsubsection{Verbos de acción en la labor periodística}

En este sentido entendemos "léxico periodístico" en dos vertientes que deben quedar bien diferenciadas desde el principio: el léxico periodístico como terminología de un lenguaje de especialización, es decir, propio de la jerga de los profesionales del periodismo en su sentido más amplio, y el "léxico periodístico" como lenguaje utilizado en los medios de comunicación, con unas características propias tales como la objetividad, la concreción, la corrección, la claridad, etc. Desde la primera perspectiva, el léxico periodístico no se comporta de manera distinta a otros lenguajes de especialización, pues se compone de tecnicismos creados por especialistas y prácticamente imposibles de entender por no iniciados en la materia ${ }^{14}$.

Es evidente que un principiante en periodismo tiene más posibilidades de entender este léxico especializado de su ámbito, que las que tiene un buen conocedor del léxico de la lengua general que no sepa nada de la especialidad en cuestión. Sólo los especialistas

\footnotetext{
${ }^{12}$ Las principales características de la información periodística son: a) Carăcter coyuntural: La información periodística depende exclusivamente de la actualidad. El mensaje periodistico ha de transmitir hechos, datos, sucesos que pertenezcan al presente o a un pasado muy próximo b) Periodicidad y frecuencia:La información periodística es periódica, no aparece una sóla vez, sino que nace cada cierto tiempo. En cuanto a la frecuencia, la información periodistica requiere continuidad, tanto en el tiempo como en los medios por los cuales se transmite dicha información, ya sean impresos, audiovisuales o tecnológicos c) Difusión social: La información periodística es susceptible de difusión, pues el mensaje informativo ha de llegar al mayor número posible de receptores. Un boletín informativo, por ejemplo, aún cuando transmita un hecho actual y novedoso, no puede ser considerado información periodistica, pues no es recepcionado por un número elevado y disperso de receptores $d$ ) Finalidad de mediación social: El primer rasgo característico de la información periodistica, es que tiene como objetivo influir en el receptor, por medio de la transmisión del mensaje informativo. La transmisión de hechos, ideas o conceptos y juicios pretende, mediante la información, influir en los receptores del mensaje informativo e) Necesidad de una técnica especializada para su transmisión: El lenguaje periodístico es un fenómeno social que repercute en casi todas las esferas de la sociedad. Los mensajes de los vehículos electrónicos son diferentes a los mensajes del periodismo impreso por determinados factores ajenos a los propios medios que les influyen. Como resultado de un conjunto de datos técnicos, políticos, culturales, etc., el mensaje periodistico ofrece caracteristicas diferenciales suficientemente acusadas según utilice como canal la prensa escrita, la radio o la televisión.

${ }^{13} \mathrm{El}$ traductor, en consecuencia, ha de conocer estas mismas reglas lingüisticas, pues, al traducir los textos, realiza la misma función que el periodista que los redactó originariamente.

${ }^{14}$ Las siguientes definiciones deben servir de ejemplos esclarecedores en ambas lenguas: Ladillo: Composición breve que suele colocarse en el margen de la plana, generalmente para indicar el contenido del texto. Eckenbriiller: eine 1-spaltige Nachricht ganz oben rechts oder ganz oben links auf der Seite, zumal auf S.1.2.
} 
pueden distinguir con precisión los términos propios de su jerga, ya que frecuentemente éstos comparten el significante con vocablos de la lengua global ${ }^{15}$.

Nuestros objetivos fundamentales deben centrarse por lo tanto en los siguientes enfoques lexicales:

1. Procurar un mayor conocimiento del mundo del periodismo y la comunicación, del sector de la radio y la televisión, de las fuentes de información, de la empresa periodística, etc.

2. la adquisición del léxico propio de las lenguas española y alemana en todos los ámbitos relacionados con dicha especialización (Cfr. C. Mast, 1998) ${ }^{16}$. Esto significa que el periodista suele transformar la exposición científica, destinada a un público reducido, en lenguaje periodístico, prestando atención a los niveles de información de los receptores del mensaje, que pueden ser, según el tipo de periódico o revista, personas cultivadas o público en general, permitiendo así la mayor comprensión posible del texto ${ }^{17}$.

\footnotetext{
${ }^{15}$ Así, por ejemplo, un error grave de redacción recibe el nombre de "Korke" en lengua alemana, mientras que una línea separadora de texto en un periỏdico es conocida como "el filete" en español. De no conocerse el significado propio del contexto periodístico en ambos casos, las consecuencias tanto para el entendimiento del texto como para la traducción a otro idioma serán lógicamente nefastas.

${ }^{16}$ Desde la segunda perspectiva, y a diferencia de otros lenguajes de especialización, como el económico, el técnico o el jurídico, donde la terminología propia es predominante en todos los textos, el lenguaje utilizado en los medios de comunicación no es terminológico. El léxico periodístico utiliza en unos los casos el lenguaje global de la lengua y en otros casos usa un lenguaje mixto, es decir, una mezcla del lenguaje común con algunos lenguajes de especialidad, según sea la naturaleza del texto. Ante una noticia de contenido económico, el léxico predominante será el económico. No obstante, dado que los medios de comunicación tienen como una de sus funciones principales dar a conocer los acontecimientos más recientes con la mayor difusión posible, suelen utilizar-con excepción de la prensa especializada- un lenguaje claro, sencillo, escueto, directo e inequivoco, para que sea accesible al mayor número de receptores posible.

${ }^{17}$ No debe olvidarse que este estilo es característico no sólo de los textos de prensa, sino también de la producción periodística en la radio y la televisión. Una característica importante para el traductor de textos periodísticos es asi lo dicen los traductores de este ámbito- la buena formación intelectual, la cultura general y el buen conocimiento de la actualidad. El periodista trata de conseguir la comprensión rápida y total del mensaje por parte de sus receptores, además de captar su atención, para lo que utiliza determinadas características en el léxico y la sintaxis empleadas. El presente trabajo parte de las nociones básicas del periodismo (la información periodística, las funciones de la prensa, la comunicación...), y analiza los tres medios de comunicación de masa más importantes, prensa, radio y televisión, escogiendo así terminologías general y particular. También a través del léxico español y alemán se analizan otras cuestiones, como las características del lenguaje periodístico, las tareas llevadas a cabo por los profesionales del periodismo, etc. Prestamos especial atención a los diversos géneros periodisticos y sus correspondencias en ambos idiomas, puesto que no siempre son equivalentes, ni en terminologia, ni en características. Lo mismo ocurre con los puestos o cargos y con la jerarquía de las plantillas de los profesionales de la prensa y la televisión en ambos paises. El periodismo responde a la demanda de comunicación del hombre, y encuentra respuesta en los medios de comunicación. Por medio de comunicación entendemos cualquier procedimiento que un emisor emplea para establecer una relación comunicativa con un receptor. Este acto comunicativo puede establecerse entre personas, microgrupos o macrogrupos, y dependiendo de la naturaleza del canal, del código, del sistema de codificación, etc., estaremos ante diferentes medios de comunicación. Aquellos medios de comunicación que se dirigen a la sociedad en general reciben el nombre de "medios de comunicación de masas" o "Mass Media". Los principales son la prensa, la radio y la televisión: • La prensa / die Presse: utiliza como soporte principal el papel o medios electrónicos (en el caso de la prensa digital). - La radio / das Radio, der Hörfunk: utiliza códigos auditivos y es el medio más inmediato. • La televisión / das Fernsehen: combina el sonido, la palabra y la imagen, siendo ésta última el elemento fundamental. De este modo podemos hablar de varios tipos de periodismo según el medio utilizado: Periodismo escrito o schriftlicher Journalismus Periodismo radiofónico o Radio-, Hörfunkjournalismus y Periodismo televisivo o
} 
Son muchas las expresiones y los verbos de acción necesarios para cubrir todas las tareas profesionales realizadas en el ámbito periodístico. Aquí se encuentran la mayoría de los verbos que comprenden las tareas de redacción, elaboración y edición de textos, así como aquellos que tienen que ver con la difusión oral de la información. Por ejemplo:

comunicar mitteilen, kommunizieren; anunciar verkünden; informar berichten, melden; plasmar acontecimientos Ereignisse darstellen; reflejar datos y hechos Daten und Fakten widerspiegeln; exponer darlegen, vortragen; desarrollar darlegen; interpretar auslegen interpretieren; reflejar reflektieren, widerspiegeln; enjuiciar beurteilen; censurar zensieren, verurteilen; juzgar (be)urteilen, erachten, schätzen; opinar meinen; recibir noticias Nachrichten empfangen; investigar untersuchen, forschen; indagar erforschen; analizar untersuchen; clasificar einordnen, klassifizieren; tratar (información) (Information) verarbeiten; evaluar bewerten; seleccionar auswählen.

\subsubsection{Léxico especializado relacionado con el periódico}

Resulta igualmente interesante hacer una especial incursión en el Léxico relativo al proceso de comunicación. Adentrémonos mediante ejemplos en esta terminología aplicable al proceso traductológico (Cfr. Medina, 2004):

el proceso de comunicación der Kommunikationsprozess; cambio de informaciones Informationen austauschen; envio de informaciones Informationen senden; recepción de información Informationen empfangen; el receptor der Empfänger; la emisora der Sender; el medio das Medium; el soporte der Träger; transmisión de una información eine Information übertragen; el canal de transmisión der Übertragungsweg; el mensaje die Botschaft; aportar un mensaje jemandem eine Botschaft bringen; recibir un mensaje eine Botschaft entgegennehmen; recibir la información eine Nachricht erhalten; la señal das Zeichen; el monólogo der Monolog; monologar einen Monolog halten; la comunicación de un solo canal die Einwegkommunikation; el diálogo der Dialog; la interactividad, el diálogo die Wechselwirkung; comunicarse con alguien mit jemandem kommunizieren; transmitir algo jemanden etwas übermitteln; la comunicación entre individuos die Mensch zu Mensch-Kommunikation; los medios de masa die Massenmedien; establecer relación con alguien sich mit jmdm. in Verbindung setzen o Verbindung mit jmdm. aufnehmen; la transmisión de noticias, mensajes die Nachrichtenübertragung; la transmisión de información die Nachrichtenübermittlung; el medio de comunicación das Kommunikationsmedium; la comunicación técnica die technische Kommunikation; medios individuales individuelle Medien; la comunicación en masa die Massenkommunikation; las técnicas de comunicación die Nachrichtentechnik; las técnicas de información die Informationstechnik; la información die Information.

\footnotetext{
Fernsehjournalismus. En algunos casos se habla de "periodismo cinematográfico": Periodismo cinematográfico o Filmjournalismus. Al periodismo escrito se le conoce normalmente con el término prensa (en alemán Presse) y esto es interesante en cuestión de terminología puesto que, aunque pueda ser lógico que no todo el periodismo escrito es prensa, en alemán se utiliza Presse con mucha más frecuencia que schriftlicher Journalismus, que puede incluso resultar en alemán un poco forzado. Asi por ejemplo el lenguaje periodístico es Pressesprache, y no *journalistische Sprache, pudiéndose utilizar también para explicar las características del lenguaje de otros medios de comunicación. Las tres formas de periodismo contribuyen a la información periodística, en alemán journalistische Information o Presseinformation.
} 


\subsubsection{Lenguaje mixto}

Las funciones de los medios de comunicación son: informar, educar y entretener. Estas funciones traen consigo la aplicación de un lenguaje mixto que conjuga, por lo tanto, las vertientes informativa, educativa y lúdica. En lengua alemana, en este contexto, no se habla de educar como erziehen, sino más bien como die Meinung bilden. Contrastemos la siguiente terminología (Cfr. Medina, 2004) ${ }^{18}$ :

la información die Information; la educación die Meinungsbildung; el entretenimiento die Unterhaltung; informar informieren, berichten; educar erziehen o (die Meinung) bilden; entretener unterhalten.

\subsubsection{Lenguaje no literal}

El lenguaje periodistico, que se caracteriza también por ser un lenguaje no literal, entendemos por lenguaje literal aquel "empleado en comunicaciones que deben ser descifradas en sus propios términos y que así deben conservarse" (Lázaro Carreter: 1980, 159-160)-, es un lenguaje que se aproxima al habla coloquial de nivel culto. Esto significa que el periodista debe escribir no como quien escribe, sino como quien está hablando. Se trata de un lenguaje apoyado en la construcción nominal, dado su carácter de eficacia comunicativa y economía de medios. Esta utilización de sintagmas nominales es, precisamente, lo que confiere al lenguaje periodístico la cualidad de concisión. Se trata de un lenguaje de producción colectiva, ya que los mensajes periodísticos entran en contacto con un número indeterminado de receptores, y son muchos los individuos que manipulan de una forma u otra el mensaje hasta que éste queda plasmado definitivamente. Es este lenguaje el que ha de ofrecer una información periodística debe ser debe ser verdadera, fiable, segura, y rápida (en el sentido de actual). La función informativa de la prensa exige novedad en los hechos, diversidad, interés, la mayor difusión posible, etc. A través del siguiente léxico se enumeran las características principales de la comunicación periodística:

la actualidad die Aktualität; actual aktuell; la novedad die Neuigkeit; novedoso neu, neuartig; la continuidad die Kontinuität o die Fortdauer; continuo ständig, fortwährend; la periodicidad die Periodizität; periódico periodisch; la regularidad die Regelmäßigkeit; la frecuencia die Häufigkeit; frecuente häufig; la difusión die Verbreitung o die Ausbreitung; difundir verbreiten; propagar ausbreiten; la objetividad die Objektivität o die Sachlichkeit; objetivo objektiv o sachlich.

\footnotetext{
${ }^{18}$ A lo largo de su historia, los medios de masa han desempeñado siempre una función social y un servicio público muy importante. De ahi la necesidad que el periodista sea consciente del papel que cumple en la sociedad, aportando sólo datos veraces y objetivos. El periodista tiene como primera misión la de informar. La información debe ser fiable, habiendo sido previamente contrastada y verificada, expuesta de modo directo y objetivamente. La formación es el resultado de la información aportada a los receptores, si bien también se consigue con la interpretación de los hechos y los juicios de valores, que normalmente se realizan a través del editorial y las noticias comentadas. Tradicionalmente, la concepción sajona de la prensa defiende un periodismo basado en la información objetiva, mientras que la concepción latina de la prensa es aquella que introduce la participación del periodista con valoraciones y fórmulas creativas de expresión. Por último, cabe destacar que normalmente las secciones de información y entretenimiento están bien diferenciadas. Excepto los periódicos, en los que la función informativa es predominante, en la radio y la televisión el entretenimiento y la distracción de los oyentes, respectivamente espectadores juega un papel de gran relevancia en nuestros dias.
} 
Por su parte, el lenguaje periodístico tiene que ser claro, para no dar lugar a malas interpretaciones, correcto, ajustándose a las reglas gramaticales y de ortografia y puntuación, y sencillo, para ayudar a la rápida comprensión y asimilación del mensaje por parte de la mayoría de las personas a las que va dirigido: "Ihr müsst so schreiben, dass euch die Marktfrau am Dom versteht, der Winzer in Rheinhessen das Blatt lesenswert findet und auch der Universitätsprofessor euch ernst nimmt ${ }^{19, \ldots}$ (Deutsch für Profis. Wege zu gutem Stil. München: Stern Bücher 1984, pág. 31).

\subsubsection{Factores e interventores de la comunicación periodística}

\section{- EMISORES Y RECEPTORES DE LA COMUNICACIÓN PERIODISTICA}

El emisor de la comunicación, por defecto, es el periodista, por ser la denominación común de la profesión. En cambio, según el medio en que trabaje y según las funciones concretas que ejerza, podemos diferenciar entre numerosos tipos de profesionales. Por ejemplo:

el periodista de agencia der Agenturjournalist; el periodista de la radio der Radiojournalist, der Hörfunkjournalist; el periodista de la televisión der Fernsehjournalist; el redactor der Redakteur; el reportero der Reporter, der Berichterstatter.

\section{- LA PRENSA: PERIÓDICOS Y REVISTAS}

Se denomina prensa al conjunto de publicaciones impresas de carácter informativo y de aparición periódica. Esto significa que la prensa comprende todos los periódicos y revistas,

\footnotetext{
${ }^{19}$ En géneros de opinión, como el artículo, la crónica, el editorial, entre otros, el lenguaje periodístico se mezcla con el lenguaje literario, perdiendo alguna de las características mencionadas arriba y adoptando un lenguaje más afectado y una sintaxis más compleja. Hemos tomado un ejemplo de estilo literarizado, absolutamente incorrecto debido a que se trata de un texto informativo. Sobran adjetivos, disyunciones, enumeraciones metáforas, etc.: La magna conferencia o sesión especial sobre el desarme comenzó en la ONU el pasado 23 de mayo [...], y ha producido un verdadero torrente de discursos, propuestas, advertencias, súplicas, manifiestos y predicamentos (?) sobre el mayor escándalo de un holocausto nuclear a escala global (?) por la loca carrera armamentista (?) que se lleva al año la astronómica cifra de 400.000 millones de dólares. Asimismo, el lenguaje tampoco no debe ser coloquial, como muestra el siguiente ejemplo: Se empiezan a desvanecer los temores de que en el senado se carguen todo el trabajo institucional del Congreso o que, cuando menos, torpedeen el consenso los llamados independientes. Sin embargo, un lenguaje culto no significa un lenguaje lleno de tecnicismos. El periodista que escribe para un público amplio debe utilizar palabras comprensibles para sus lectores. A continuación se muestra un ejemplo de cómo no debe escribir el periodista: Innovation des Konsums durch Investition in marketinggerechte Verkaufsräume und Kosten senkende Arbeits- und Abrechnungsabläufe wird der Beitrag des Handels zur Konjunkturbelebung sein. Los siguientes adjetivos describen cómo debe ser en lenguaje de la información periodística: claro kiar, deutlich; correcto korrekt; eficaz wirksam; concreto konkret; fluido fliissig; directo direkt, unmittelbar; conciso knapp, bündig; inequivoco eindeutig; objetivo objektiv, sachlich; ordenado ordentlich; escueto knapp; sobrio nüchtern; llano, sencillo schlicht, simple einfach; aséptico aseptisch; accesible zugänglich; divulgativo allgemein verständlich; detallado ausführlich; imparcial unparteiisch; comprensible verständlich. Es importante mencionar que la traducción de alguno de estos adjetivos es, en algunos casos, intercambiable (por ejemplo einfach puede traducirse por simple o por sencillo), de modo que no se puede establecer una única relación bilateral entre muchos de ellos. Como ha sido mencionado con anterioridad, estos adjetivos se corresponden a géneros periodísticos informativos, tales como la noticia o el reportaje objetivo. Otros géneros, como los de opinión o los artículos de la prensa amarilla, pueden teñirse de otras características contrarias. Por ejemplo: parcial parteiisch; sensacionalista sensationell, skandalös; frivolo frivol. Al lenguaje de la radio y la televisión se le pide además que sea espontáneo y atractivo, para motivar a los oyentes o espectadores.
} 
con independencia de su naturaleza, periodicidad y contenido, siempre que se ajusten al hecho de informar. Así: los medios die Medien. Tipos de revistas según su contenido:

la revista die Zeitschrift, das Blatt, die Illustrierte; el magazine das Magazin; la revista femenina die Frauenzeitschrift; la revista de información die Nachrichtenmagazin; la revista del corazón die Regenbogenpresse; la revista especializada die Fachzeitschrift; la revista divulgativa die Publikumszeitschrift; la prensa sensacionalista, el Amarillismo die Sensationsmache; la presentación gráfica (del periódico) die Aufmachung; el ejemplar das Exemplar; la tirada, la edición die Ausgabe.

\section{- LAS AGENCIAS DE PRENSA}

Las agencias de prensa son organizaciones destinadas a la provisión de noticias y su transmisión a clientes determinados, generalmente medios informativos de prensa, radio y televisión. Pueden ser de carácter público o privado ${ }^{20}$.

\section{- LA NOTICIA: TIPOS DE NOTICIAS}

El vocabulario relacionado con los tipos de noticias existentes y sus equivalencias es:

Noticias locales Lokalnachrichten; Noticias regionales Regionalnachrichten; Noticias nacionales überregionale Nachrichten; noticias internacionales internationale Nachrichten; la agencia de noticias die Nachrichtenagentur; noticias de la prensa Pressenachrichten; una noticia de prensa eine Pressemeldung.

\section{- ELEMENTOS DE LA NOTICIA}

Atendiendo al vocabulario destacamos la siguiente terminología:

los Titulares die Schlagzeilen; el cintillo die Dachzeile, die Kopfzeile; el antetitulo die Ober-oder Überzeile; el título die Überschrift, die Hauptzeile, Titelzeile, Headline; el subtítulo die Unterzeile; la entradilla der Vorspann, das Einführungsresumée; el cuerpo der Grundtext,

\footnotetext{
${ }^{20}$ Estas agencias son: - Reuter, de Reino Unido, controlada por una comisión paraestatal integrada por representantes de la Commonwealth. Puede verse su página web en: www.reuters.com (tiene versión en español) • Associated Press, de Estados Unidos, controlada por una cooperativa de los más importantes diarios neoyorquinos. Puedes encontrarla en: www.ap.org - United Press International, de Estados Unidos, privada. Enlace: www.upi.com - France Press, de Francia, estatal. Podemos ver su página web también en lengua española o en lengua alemana www.apf.com • Tass, agencia oficial de la ex-Unión Soviética. Enlace: www.itar-tass.com (página web en ruso o en inglés) Estas cinco agencias controlan prácticamente el mercado internacional de la noticia. Por ello, para hacer frente a esta situación y cuanto pueda suponer de colonización ideológica, casi todos los estados han creado agencias nacionales que sirven de filtro entre la información facilitada por las agencias mundiales y la que reciben los medios informativos de cada pais. Las agencias de prensa de España son: - Agencia EFE: www.efe.es - Europa Press: www.europapress.es - Atlas-News: www.atlas-news.com - Colpisa: www.colpisa.com - Avant Press: www.avantpress.es • Diálogo Iberoamericano. A. Universitaria de Noticias: www.dialogo.ugr.es • Servimedia: www.servimedia.es. Las agencias de prensa de Alemania son: - Deutsche Presse Agentur www.dpa.es - PRESSE.COM: www.presse.com (Presseverteiler) - PRESSLINE (Datenbank für Pressemitteilungen von deutschen Firmen): www.pressline.com/ge home.htm - AGENCE FRANCE PRESS (afp): Deutsche Dienste der afp. http://.w3rsc.afp.com/afp vd. Para acceder a las demás agencias del mundo, se puede entrar en las siguientes bases de datos digitales: - En lengua española: http://www.pressnetweb.com/index.htm. Es muy recomendable navegar en esta página en lengua española debido a la cantidad de sus enlaces. - En lengua alemana: http://www.franc.ch/printmed.htm\#Presseagenturen. Esta última contiene una base de datos con los medios de comunicación en lengua alemana de todo el mundo, además de un impresionante banco de datos con informaciones de otro tipo.
} 
Lauftext, der Hauptteil; el ladillo der Randtitel, die Randbemerkung, die Marginalie; la firma die Autorenzeile; el pie de foto die Bildunterschrift; la firma de foto die Bildquelle; la cabecera der Zeitungskopf.

\section{- OTRO VOCABULARIO RELACIONADO CON EL PERIÓDICO}

Vocabulario:

la mancheta das Impressum; el sumario der Inhaltskasten, das Inhaltsverzeichnis; la información de apertura die Spitzenmeldung, der Aufmacher; número de ejemplar laufende Nummer; la composición der Bleisatz, Schriftsatz.

\section{- OTROS GÉNEROS DEL PERIODISMO ESCRITO}

\section{Vocabulario:}

el reportaje der Bericht, die Reportage, la entrevista das Interview; el artículo der Artikel; el artículo de opinión die Meinung; el artículo de fondo der Grundartikel; el editorial der Leitartikel; la crítica die Kritik; el comentario der Kommentar, die Glosse; la columna die Kolumne; la crónica der (aktuelle) Bericht; crónica de sucesos (aktueller) Bericht über kriminelle Vorfälle; crónica deportiva Sportbericht; crónica local Lokalbericht; crónica taurina Bericht über Stierkämpfe.

\section{CARACTERÍSTICAS DEL LENGUAJE PERIODÍSTICO ESPAÑOL}

El lenguaje periodístico ha de atender, en líneas generales, a las características que enumeramos a continuación: 1. Claridad: esta claridad surge con la correcta elección de las palabras al redactar. Si el redactor utiliza un vocabulario preciso y con propiedad, los conceptos transmitidos en el mensaje informativo serán ajustados, y el receptor no interpretará dicho mensaje de otra forma que no sea aquella en la que el periodista pretende que se interprete la información transmitida. 2. Fluidez: el lenguaje periodístico ha de ser directo, debe ir al grano. Por ello, siempre es preferible la utilización de oraciones cortas, sin una sintaxis excesivamente complicada. Al utilizar frases subordinadas o extensiones, sólo se debe pretender aclarar el mensaje transmitido por la oración principal, sin que ello perjudique la comprensión del lector, oyente o televidente del mensaje periodístico. 3 . Equilibrio: Salvo excepciones, especialmente las concernientes al periodismo especializado, el lenguaje periodístico ha de ser un lenguaje intermedio entre el culto y el popular. 4. Expresividad: el vocabulario del redactor ha de ser lo más amplio posible, no sólo en el caso de periodistas no especializados, esto es, que cubran una información heterogénea, sino también de aquellos que ya tienen una especialidad y se dedican a un solo campo informativo (deportes, crítica taurina, política, economía, etc.). Esta creatividad y riqueza léxica no implica que se deba abandonar la objetividad. El lenguaje periodístico no pretende emitir juicios personales, sino informar, transmitir unos hechos determinados a un número indeterminado de receptores. 5. Corrección gramatical: el lenguaje periodístico, ya lo hemos señalado con anterioridad, ha de atenerse a las normas gramaticales de la lengua en la cual se redacta. Además de saber qué se escribe, es necesario e imprescindible saber cómo se escribe. 6. Adecuación al género y al tratamiento técnico del mensaje: además de todas las normas anteriores, el redactor -y también el traductor de textos periodísticos- ha 
de considerar las diferencias existentes entre los distintos géneros periodísticos, por ejemplo, entre los informativos y los interpretativos, entre los informativos e interpretativos y los de opinión, o entre los géneros de opinión y los artículos de escritores que publican habitualmente en prensa. 7. Orden: $e$ l texto periodístico ha de tener unidad y orden. Este orden se consigue siguiendo los siguientes pasos: en primer lugar, el redactor ha de tener un planteamiento previo de lo que quiere comunicar; a continuación, debe realizar un esquema de la información que pretende dar a conocer, lo que supone plantear la idea principal y las secundarias que sean útiles para la elaboración del texto; por último, se ha de repasar y revisar todo lo escrito. 8. Captación del receptor: la principal función, además de la de informar, es la de captar la atención del lector, el oyente o el televidente. Y esta atención ha de conseguirse desde el comienzo del mensaje periodístico, ya sea en las primeras líneas del texto o en las primeras frases enunciadas en los medios radiofónicos o televisivos.

\subsection{Elementos morfosintácticos}

a) Rasgos morfosintácticos

El léxico periodísitico español se caracteriza además por presentar los siguientes rasgos morfosintácticos:

1. Alargamiento de las oraciones mediante perífrasis, aposiciones, incisos, frases explicativas, etc.

2. Abundancia de la voz pasiva.

3. Tendencia a colocar el sujeto al final de la frase.

4. Mezcla del estilo directo y el indirecto.

\subsection{Elementos léxicos}

b) Rasgos léxicos

1. Uso de numerosos extranjerismos (especialmente anglicismos), y de calcos semánticos.

2. Empleo de siglas y acrónimos.

3. Empleo de eufemismos: hostilidades (en lugar de guerra), incursión aérea (en lugar de bombardeo).

\subsection{Elementos retóricos}

c) Rasgos retóricos

Es frecuente encontrar numerosas figuras retóricas en el lenguaje periodístico. Las más importantes son las metáforas, las metonimias, las personificaciones y las hipérboles. 


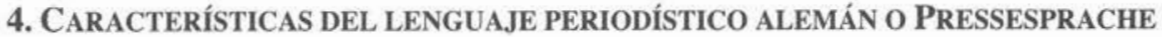

El lenguaje periodístico alemán participa de las características arriba mencionadas ${ }^{21}$.

\subsection{Elementos morfosintácticos}

a) Rasgos morfosintácticos

1. Tendencia a la reducción o el acortamiento de la frase, especialmente en los titulares de las distintas noticias. Esta es una característica general del alemán escrito, si bien se acusa aún más en el caso de textos periodísticos.

2. Abundancia de la voz pasiva.

3. Uso de numerosas perífrasis verbales.

4. Otro rasgo muy característico del lenguaje periodístico alemán afecta principalmente a la distribución de la frase. Entre éstos, caben destacar las figuras denominadas Setzungen, Einfachsätze, Reihe, y Gefüge: Setzungen sind grammatikalisch unvollständige Äußerungen, in denen ein konstitutives Element fehlt, z. B. das Verb oder das Subjekt ("Überall Staus", "Selbstverständlich"). Einfachsätze bestehen aus nur einem Hauptsatz, ohne Nebensatz oder satzwertigen Infinitiv ("Bielefeld mauert in Köln", (...) ). Reihen sind zwei oder mehr miteinander verbundene,grammatisch vollständige Hauptsätze ("60 Personen wurden festgenommen, gegen 22 wurden Haftbefehle erlassen"). Satzgefüge weisen außer dem Hauptsatz wenigstens einen Nebensatz oder satzwertigen Infinitiv auf ("In den polnischen Kirchen wurde gestern ain Hirtenbrief verlesen, in dem die Bischöfe die Gläubigen auffordern, für die Erhaltung der Freiheit der Nation zu beten") Lüger (1983: 25).

5. Estilo nominal. Este es un recurso muy frecuente en el lenguaje periodístico en general.

\subsection{Elementos léxicos}

b) Rasgos léxicos

1. Uso de numerosos extranjerismos (Fremdwörter), especialmente anglicismos.

2. Empleo de siglas y acrónimos.

3. Empleo de eufemismos.

\subsection{Elementos retóricos}

c) Rasgos retóricos

El principal recurso retórico empleado en el lenguaje periodístico es el de la personificación.

${ }^{21}$ Véase ap. II.2.1. 
d) Ejemplificación lexical en el ámbito textual

La ejemplificación referente al ámbito textual se basa, en unos casos, en expresiones literales específicas del lenguaje periodísitico y, en otros casos, en recursos estilisticos empleados en el ámbito de este lenguaje con fines específicos.

\subsubsection{Términos complementarios y expresiones reiterativas}

La ejemplificación corresponde a componentes puramente complementarios o reiterativos en lengua alemana y española ${ }^{22}$ :

TEXT0 1 (LONDONER ANSCHLÄGE) VOCABULARIO: Sprengsätze $\rightarrow$ der Sprengsatz $\rightarrow$ mecanismo de arranque y material explosivo Selbstmordattentäter $\rightarrow$ der Selbstmordattentäter $\rightarrow$ terrorista suicida. Ejemplos: 1) Unterschlupf gesucht hätten $<$ Unterschlupf suchen $>$ refugiarse 2) Sie stammten aus dem Umfeld der mutmaßlichen Terroristen,..$<$ aus dem Umfeld (der mutmaßlichen Terroristen) stammen $>$ ser del entorno de los presuntos terroristas.

TEXT0 2 (NACH DER TOUR) Ejemplos: 1) ... war diese Ehre nicht vergönnt $<$ die Ehre vergönnen $>$ conceder el honor 2) Getrübt wurde dieser Jubeltag... < den Jubeltag (die Freude) trüben $>$ aguar la fiesta.

TEXT0 3 (ZABEL GIBT RÄTSEL AUF) VOCABULARIO: Teamgefährten $\rightarrow$ der Teamgefährten $\rightarrow$ el compañero de equipo Gesamtwertung $\rightarrow$ die Gesamtwertung $\rightarrow$ la clasificación general. Ejemplos: 1) Zabel gibt Rätsel auf $<$ Rätsel aufgeben $>$ encerrar un misterio 2) In Verbindung gebracht $<$ jmd. In Verbindung bringen mit... $>$ asociar a alguien con...

TEXT0 4 (FDP FINDET AUSWEG AUS MEHRWERTSTEUERERHÖHUNG)

VOCABULARIO: den Ich-AGs $\rightarrow$ die Ich-AG $\rightarrow$ el autónomo den ABM-Zuschüssen $\rightarrow$ der ABM-Zuschuss $\rightarrow$ subvención fomento de empleo. Ejemplos: 1) Es sehe Einsparungen bei $[\ldots]$ vor $<$ Einsparungen vorsehen $>$ prever recortes [...] 2) sind vom Willen beseelt $<$ vom Willen beseelt sein $>$ estar inspirado por la voluntad.

TEXTO 5 (DEBATTE ÜBER LUFTSICHERHEIT NACH FLUGZEUGABSTURZ IN BERLIN)VOCABULARIO: Überflugverbote $\rightarrow$ Das Überflugverbot $\rightarrow$ restricción de campo aéreoLänderhoheit $\rightarrow$ Die Länderhoheit $\rightarrow$ competencia de los Länder. Ejemplos: 1) angefachte Debatte $<$ eine Debatte anfachen $>$ provocar un debate 2) dies dürfe kein Tabu [...] sein $<$ kein Tabu sein dürfe $>$ no deber ser intocable.

TEXTO 6 (KURZZEIT-PARKPLATZ FÜR PRIVATANLEGER) Ejemplos: 1) auf so genannte Asset Backed Securities setzen > apostar por los llamados "Asset Backed Securities" 2) [...] kommen [Anleger bereits ab 10000 Euro] zum Zuge $<$ zum Zuge kommen $>$ entrar en el juego.

TEXTO 7 (2500 FOLGEN "VERBOTENE LIEBE ") Ejemplos: 1) in dieses Vakuum stößt die ARD < in dieses (ein) Vakuum stoßen > ocupar un vacío 2) Jeder kann nach seiner Façon glücklich werden $<$ nach seiner Façon glücklich werden $>$ hacerse feliz a su manera. TEXTO 8 (NEUE CHANCEN IN DER SCHMERZBEHANDLUNG) Ejemplos: 1) Skeptisch stimmt, dass [...] $>$ da de pensar que 2) [...]ein Trend in eine positive Richtungzeichnet sich (jedoch) $a b>[\ldots]$ perfila una tendencia positiva.

${ }^{22}$ Los textos empleados a modo de ejemplo se reflejan en el ap. III. Anexo. 
TEXT 10 (GUTE FRAGE, SCHLECHTE ANTWORTEN) Ejemplo: in einen Topf geworfen werden $>$ ser metido en el mismo saco.

TEXT 11 (SCHLEICHENDER ZENTRALISMUS-KÖHLERS REDE) Ejemplo: spielte damit auf dessen Äußerungen $>$ aludir a las declaraciones de...

TEXTO 12 (GELDWÄSCHEVERDACHT IN DER COMMERZBANK) Ejemplos: 1) ist in einen internationalen Geldwäscheskandal verstrickt < in einen Skandal verstrickt sein $>$ estar metido en un escándalo 2) Das kratzt am Ruf $<$ am Ruf kratzen $>$ desacreditar.

TEXTO 13 (IMMER MEHR RENTNER LEBEN IM AUSLAND) Ejemplo: hat während seines Arbeitslebens Ansprüche gegenüber ausländischen Rentenversicherungssystemen erworben < (Renten)-Ansprüche erworben haben $>$ haber adquirido reivindicaciones (de pensión o derechos).

TEXTO 14 (RADIKALPROGRAMM FÜR DEN ARBEITSMARKT) Ejemplos: 1) bei näherer Betrachtung löst es sich in Nichts auf $>$ mirándolo de cerca se desinfla (desaparece / acaba en cero) 2) sie blieben auch die Antwort schuldig < die Antwort schuldig bleiben > no contestar / no saber respuesta.

\subsubsection{Adecuación en la interpretación oracional: variantes procedentes del espanol vs. alemán}

En este apartado se ejemplifican a modo de esquema estructuras complejas que presentan un esquema reiterativo. Estas estructuras pueden simplificarse a la hora de su traducción por gerundios, infinitvos con artículo o participios absolutos, respectivamente concertados en los casos de traducción directa al español, y en los casos de traducciones inversas al alemán puede recurrirse al empleo de verbos intransitivos acompañados de determinados adverbios o de sustantivos con preposición como alternativa a estructuras hipotacticas equivalentes a construcciones absolutas. Véanse:

TEXTO 1 (LONDONER ANSCHLÄGE) Ejemplos: 1) Die Polizei habe keine Hinweise darauf, dass die Terroristen das Land verlassen hätten > la policía no tiene indicios de que los terroristas hayan abandonado el país 2) Einem Bericht der "Times" zufolge nimmt die Polizei an, dass die Verdächtigen in London lebten und ostafrikanischer Herkunft sind > según una noticia del "Times", la policía supone que los sospechosos viven en Londres y son de origen africano-oriental.

TEXT 3 (ZABEL GIBT RÄTSEL AUF) Ejemplos: 1) Dafür die Kräfte sparen, die man früher für Zabels Etappensiege verbraucht hat $>$ ahorrar las fuerzas que anteriormente se gastaron (gastadas) en las victorias de Etapa de Zabel 2) [...] Woche angedeutet, dass er damit nicht zufrieden sei und er bessere Offerten habe $>$ no obstante, ya había señalado hace una semana que no estaba contento con eso y que tenía mejores ofertas.

TEXT 4 (FDP FINDET AUSWEG AUS MEHRWERTSTEUERERHÖHUNG) Ejemplos: 1) Die "Berliner Zeitung" berichtet über ein Konzept, das FDP-Generalsekretär Dirk Niebel gemeinsam mit dem Finanzfachmann Hermann Otto Solms erarbeitet hat > El BZ informa sobre un proyecto que ha elaborado Dirk Niebel, secretario general del FDP, junto con el experto financiero HOS [sobre un proyecto elaborado por...]2) Nach Schätzung der FDP ließen sich sogar über 30 Milliarden Euro sparen, wenn die Bundesagentur ganz abgeschafft würde > según cálculo del FDP se podrían ahorrar incluso más de 30 millones de Euros si se cerrara definitivamente la Agencia Federal [cerrando definitivamente...]. 
TEXT 5 (DEBATTE ÜBER LUFTSICHERHEIT NACH FLUGZEUGABSTURZ IN BERLIN) Ejemplo: Eine pauschale Regelung zu Überflugverboten gibt es nicht, weil dies Länderhoheit $>$ Un reglamento general respecto a las restricciones del e.a. no existe, porque es un derecho soberano de las autonomías [siendo aquellas derecho soberano de los Länder].

TEXT 6 (KURZZEIT-PARKPLATZ FÜR PRIVATANLEGER) Ejemplo: Das ist um so erstaunlicher, da die Renditen inzwischen recht überschaubar sind > eso sorprende tanto más, puesto que los beneficios ya son bastante transparentes [siendo los beneficios ya bastante transparentes].

TEXT 7 (2500 FOLGEN "VERBOTENE LIEBE ") Ejemplos: 1) Wenn man sich durch Soaps wie "Verbotene Liebe", "Marienhof", "Unter uns" oder "Gute Zeiten, Schlechte Zeiten" zappt, hat man das Gefühl, die sind austauschbar > si uno zapea entre culebrones como "Verbotene Liebe", "Marienhof", "Unter uns" o "Gute Zeiten, Schlechte Zeiten", tiene la sensación de que sean intercambiables [zapeando entre culebrones..., uno tiene la sensación de su intercambiabilidad] 2) Man kann mal sehen, wohin man kommt, wenn man bestimmte Grenzen überschreitet > se puede ver adonde llega uno, si transgrede determinados límites [transgrediendo determinados límites].

TEXT 8 (NEUE CHANCEN IN DER SCHMERZBEHANDLUNG) Ejemplos: 1) Krankheiten zeigen sich (demnach) oft an Orten, an denen sie gar nicht stattfinden $>$ las enfermedades se hacen visibles en zonas en las que no tienen lugar 2) Insgesamt kommen die Autoren der Düsseldorfer Studie zu dem Schluß, daß man die Methode von Huneke in der Behandlung chronischer Rückenschmerzen empfehlen kann > en resumen, los autores del Estudio de Düsseldorf llegan a la conclusión de que el método de Huneke es recomendable en el tratamiento de molestias crónicas de espalda.

TEXT 11 (SCHLEICHENDER ZENTRALISMUS-KÖHLERS REDE) Ejemplos: 1) "Als sicher gilt, daß nach dem 18. September ein neuer Versuch zur Reform des Bund-LänderVerhältnisses unternommen wird" > "Parece cierto que después del 18-S se emprenda un nuevo intento de reformar la relación entre Estado y Autonomías" 2) "Das Bund-LänderVerhältnis ist angespannter geworden, seit sich nach dem Umzug von Regierung und Parlament nach Berlin ein mentaler und sprachlicher Zentralismus breit macht" > La relación Estado-Autonomía se ha vuelto más tensa, desde que se impusiera un centralismo mental y lingüísitico después de la mudanza de Gobierno y Parlamento a Berlín.

TEXTO 12 (GELDWÄSCHEVERDACHT IN DER COMMERZBANK) Ejemplos: 1) Die Commerzbank besaß die Holding nur treuhänderisch für die Anleger, wie aus der Bank versichert wird > El Commerzbank tuvo el holding sólo en función de fiduciario de los inversores, como aseguraron desde el banco $>$ Según declaracoines del banco el Commerzbank sólo tuvo el holding en función de fiduciario 2) Eine zweite Schaltstelle der Investoren war eine Kapitalanlagegesellschaft in Frankfurt, die zwei Mitarbeiter der Bank nach ihrem Ausscheiden im Jahr 2002 gegründet hatten > Un segundo centro de gestión de los inversores fue una sociedad inversionista en Frankfurt, la que han fundado dos colaboradores del banco después de su dimisión en el $2002>\ldots$ fundado por dos colaboradores del banco tras su dimisión en el 2002.

TEXTO 13 (IMMER MEHR RENTNER LEBEN IM AUSLAND) Ejemplo: Mit einer Reihe von Staaten, die nicht der EU angehören, hat Deutschland bilaterale Sozialversicherungsabkommen abgeschlossen $>$ Con una serie de paises que no pertenecen a la UE (no pertenecientes a la UE, ha concluido tratados de seguridad social bilaterales > 
Sigue siendo asunto de los estados cómo plantean sus sistemas de seguridad social (qué forma dan a sus sistemas de S.S)

TEXTO 14 (RADIKALPROGRAMM FÜR DEN ARBEITSMARKT) Ejemplos: 1) Werde die BA ganz abgeschafft, seien weitere Effizienzgewinne von 15 Milliarden Euro möglich, erklärten FDP-Generalsekretär Dirk Niebel und der Finanzpolitiker Hermann Otto Solms > En caso de que se cerrara por completo la BA, serían posibles beneficios de eficiencia de 15 mil millones de Euros, declararon... 2) Da viele Maßnahmen der aktiven Arbeitsmarktpolitik über mehrere Jahre laufen, schlügen die Einspareffekte selbst bei einem sofortigen Maßnahmestopp erst im Zeitablauf an > Los efectos de ahorro no se harían notar antes de $\mathrm{x}$ tiempo, ni en caso de un parón inmediato de las medidas, puesto que muchas ${ }_{-}^{*}$

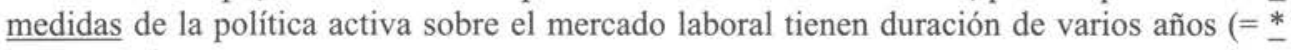
programas).

\section{ANEXO DE TEXTOS}

\section{TEXTO 1}

\section{LONDONER ANSCHLÄGE}

Rucksackbomber untergetaucht - weitere Anschläge befürchtet

Drei Festnahmen hat Scotland Yard im Zusammenhang mit den jüngsten Anschlägen in London vermeldet. Die gesuchten Rucksackbomber bleiben aber verschwunden. Es sei möglich, dass die Männer bei Komplizen Unterschlupf gesucht hätten und nun weitere Attentate planten, berichtet die BBC. London.

Die Polizei habe keine Hinweise darauf, dass die Terroristen das Land verlassen hätten, meldet der Sender BBC. Scotland-Yard-Chef Ian Blair hatte die Ermittlungen gestern als "Rennen gegen die Zeit" bezeichnet. [...] Die Veröffentlichung von Fahndungsfotos der vier verhinderten Selbstmordattentäter hat bislang keine Ergebnisse gebracht. Die Polizei hat zwar drei Verdächtige festgenommen, nach Angaben von BBC und der britischen Nachrichtenagentur PA handelt es sich dabei aber nicht um die Haupttăter. Sie stammten aus dem Umfeld der mutmaßlichen Terroristen, hieß es. Einem Bericht der "Times" zufolge nimmt die Polizei an, dass die Verdächtigen in London lebten und ostafrikanischer Herkunft sind.

\section{DIE WELT}

25. Juli 2005

\section{TEXTO 2}

\section{NACH DER TOUR}

Ullich begeistert gefeiert

Die Popularität von Jan Ullrich ist ungebrochen. Beim üblichen Empfang nach der Tour in Bonn war der Dritte der Frankreich-Rundfahrt unumstrittener Star. Getrübt wurde dieser Jubeltag nur durch Erik Zabel,

den es offenbar wegzieht von T-Mobile. Bonn.

Die Nacht war kurz, der Jubel gewaltig. Rund 5000 Fans bereiteten Jan Ullrich und seiner T-Mobile-Mannschaft heute einen begeisterten Empfang vor der Firmenzentrale des Hauptsponsors in Bonn-Beuel. Dieses Procedere ist Tradition beim Team in Magenta, direkt einen Tag nach Ende der Tour de France gibt es eine Feier in der früheren [...]. In Bonn duften sich dann Ullrich und seine Teamkollegen ins Goldene Buch der Stadt eintragen. Nur Andreas Klöden war diese Ehre nicht vergönnt: Er musste sich nach seinem Kahnbeinbruch bei der Tour einer Untersuchung in der UniklinikFreiburg unterziehen. [...].

DIE WELT

27. Juli 2005 


\section{TEXTO 3}

\section{ZABEL GIBT RÄTSEL AUF}

Unklar ist auch die Personalie Erik Zabel. Der Sprinter aus Unna wurde in diesem Jahr nicht zur Tour mitgenommen, die Mannschaft sollte sich hundertprozentig auf den Gesamtsieg konzentrieren und dafür die Kräfte sparen, die man früher für Zabels Etappensiege verbraucht hatte. Ein neues T-Mobile-Angebot liegt Zabel bereits vor, allerdings hatte er bereits vorige Woche angedeutet, dass er damit nicht zufrieden sei und er bessere Offerten habe. Mittlerweile wird der Sprinter mit der italienischen Mannschaft Domina Vacanza in Verbindung gebracht, die auch an Zabels Teamgefährten Rolf Aldag und Jan Schaffrath interessiert sein soll. "Wir wollen bis zum Weltcup am Sonntag in Hamburg die Gespräche mit Erik. [...] Etappe gewinnen, der Amerikaner Levi Leipheimer fuhr auf den sechsten Rang der Gesamtwertung. Zudem kam das Team komplett in Paris an. "Mehr konnten wir wirklich nicht erreichen", sagte Teamchef Hans-Michael Holczer. [...].

DIE WELT

22. Juli 2005

\section{TEXTO 4}

\section{FDP FINDET AUSWEG AUS MEHRWERTSTEUERERHÖHUNG}

Liberale schlagen Einsparungen bei der Bundesagentur von jährlich über 15 Milliarden Euro vor Berlin - Die FDP will mit Milliarden-Einsparungen bei der Bundesagentur für Arbeit eine Mehrwertsteuererhöhung überflüssig machen. Die "Berliner Zeitung" berichtet über ein Konzept, das FDP-Generalsekretär Dirk Niebel gemeinsam mit dem Finanzfachmann Hermann Otto Solms erarbeitet hat. Es sehe Einsparungen bei der Bundesagentur von jährlich über 15 Milliarden Euro vor. Auf diese Weise ließe sich der Beitrag zur Arbeitslosenversicherung auch ohne Mehrwertsteuererhöhung von 6,5 [...]. Niebel und Solms schlagen dem Bericht zufolge Kürzungen bei den Personalservice-Agenturen, den ABM-Zuschüssen, den Ich-AGs und der Altersteilzeit vor. [...] Nach Schätzung der FDP ließen sich sogar über 30 Milliarden Euro sparen, wenn die Bundesagentur ganz abgeschafft würde. [...] Im Interview der "Berliner Zeitung" bekräftigte Niebel das Nein der FDP zur Mehrwertsteuererhöhung. "Wir sind vom Willen beseelt, alles zu tun, um Steuererhöhungen zu verhindern", sagte er. Eine Erhöhung zu Gunsten der Arbeitslosenversicherung sei "der gleiche Unsinn" wie bei der Ökosteuer. "Man nimmt den Menschen immer mehr Geld weg, um es in ein marodes System zu stecken. Dadurch übertüncht man die Reformnotwendigkeiten und verlagert die Probleme des Systems in die Zukunft", kritisierte der Generalsekretär.

DIE WELT

29. Juli 2005

\section{TEXTO5}

\section{DEBATE ÜBER LUFTSICHERHEIT NACH FLUGABSTURZ IN BERLIN}

Berlin - Bundesverkehrsminister Manfred Stolpe (SPD) will als Konsequenz aus dem Flugzeugabsturz am Reichstag Flüge von Hobbypiloten und Privatfliegern über der Berliner Innenstadt verbieten. "Wir werden über dem Regierungsviertel ein Flugbeschränkungsgebiet für Sichtflüge einrichten", sagte er nach Beratungen mit Berlins Innensenator Ehrhart Körting (SPD). Stolpe geht davon aus, daß sich das Gebiet am S-Bahn-Ring rund um die City orientiere. Sein Ministerium könne die Zone ohne Zustimmung von Bundestag, Bundesrat oder Berlin einrichten.

[...] Auch Brandenburgs Innenminister Jörg Schönbohm (CDU) sprach sich dafür aus. Eine pauschale Regelung zu Überflugverboten gibt es nicht, weil dies Länderhoheit ist. Deshalb muß von Spielort zu Spielort darüber entschieden werden. "Wir versuchen durch entsprechende Anträge bei den Behörden, solche Verbote zu forcieren. Aus Sicherheitsgründen ist es in unserem Interesse, daß es Überflugverbote gibt", sagte Wolfgang Niersbach, Geschäftsführender Vizepräsident des WM-Organisationskomitees, dieser Zeitung. [...] Die von der Union angefachte Debatte sei "absolut überflüssig". Kanzlerkandidatin Angela Merkel sagte hingegen, dies dürfe bei entsprechender Gefahr kein Tabu sein.

MLU

ARTIKEL ERSCHIENEN AM MO, 25. JULI 2005 


\section{TEXTO 6 \\ KURZZEIT-PARKPLATZ FÜR PRIVATANLEGER \\ Geldmarkt-Fonds sind trotz niedriger Renditen gefragt - Gebühren als entscheidendes Kauf-Kriterium von Nando Sommerfeldt}

68 Milliarden Euro - mit dieser stolzen Summe sind die Deutschen in Geldmarktfonds investiert. Finanzexperten wundern sich immer wieder über die gewaltigen Volumina und die stetig anhaltenden Mittelzuflüsse. Allein im zweiten Quartal dieses Jahres sind drei Mrd. Euro dazugekommen. Das ist um so erstaunlicher, da die Renditen inzwischen recht überschaubar sind. Denn Geldmarktfonds bieten letztlich die Verzinsung von sehr kurzfristigen Anlageformen. [...] Die besten Renditen erzielen Fonds, die auf so genannte Asset Backed Securities setzen. "Dahinter verbergen sich illiquide Forderungen etwa aus Hypotheken oder Automobilfinanzierungen, die in handelbare, verzinsliche Wertpapiere umgewandelt wurden", erklärt Fondsanalyst Wetter. [...] Nur beim zweitplazierten Kepler Asset Backed Securities kommen Anleger bereits ab 10000 Euro zum Zuge. "Das Risiko von Kursverlusten ist zwar auch hier sehr gering, aber theoretisch besteht es", weist Analyst Wetter auf den Unterschied hin. "Ein Mehrertrag ist immer mit mehr Risiko verbunden." Außerdem: Durch das aktivere Management sind auch die Gebühren etwas höher. Spezialisiert auf Tabubrüche.

MLU

ARTIKEL ERSCHIENEN AM MO, 25. JULI 2005

\section{TEXTO 7}

SPEZIALISIERT AUF TABUBRÜCHE

2500 folgen "verbotene liebe" - medienforscher Jens Lönneker über psychologische Erfolgsrezepte -Iinterview von Antje Hildebrandt

[...] DIE WELT: Wenn man sich durch Soaps wie "Verbotene Liebe", "Marienhof". "Unter uns" oder "Gute Zeiten, Schlechte Zeiten" zappt, hat man das Gefühl, die sind austauschbar. [...].

Lönneker: Nein, ich würde eher von einem psychohygienischen Effekt sprechen: Man kann mal sehen, wohin man kommt, wenn man bestimmte Grenzen überschreitet. [...].

Lönneker: In gewisser Weise schon. Die 68er-Generation hat uns eine neue Freiheit gebracht: Jeder kann nach seiner Facon glücklich werden. Viele Jugendliche sind damit aber überfordert. Ihre Eltern sind oft keine Vorbilder. Entweder, sie sind mit ihren eigenen Idealen gescheitert, oder es mangelt ihnen an Autorität. DIE WELT: Und in dieses Vakuum stößt die ARD mit Ersatzmüttern -vätern? Lönneker: Die Soap funktioniert eher wie ein Märchen. Dort ist es doch auch so: Jede Figur vertritt ein eigenes Konzept. Und der Zuschauer pickt sich daraus etwas heraus. [...] DIE WELT: Wo liegt der Fokus Ihrer Untersuchungen für die ARD? Lönneker: Wir zeigen ausgewählten Testpersonen neue "Verbotene Liebe"-Folgen und befragen Sie anschließend. $[\ldots]$.

MLU

ARTIKEL ERSCHIENEN AM DI, 26. JULI 2005

\section{TEXTO 8}

\section{NEUE CHANCEN IN DER SCHMERZBEHANDLUNG \\ Bei der Neuraltherapie spritzen Ärzte Betäubungsmittel in die Haut und wollen so Beschwerden lindern von Jörg Zittlau}

Berlin - [...] Krankheiten zeigen sich demnach oft an Orten, an denen sie gar nicht stattfinden. [...] Dennoch: Skeptisch stimmt, daß einige Neuraltherapeuten ihr Verfahren bei mehr als 300 unterschiedlichen Leiden empfehlen - von der Fehlgeburt bis zum Geschwür des Zwölffingerdarms. Auch die wissenschaftlichen Daten zur Neuraltherapie sind spärlich, ein Trend in eine positive Richtung zeichnet sich jedoch ab. [...]. Insgesamt kommen die Autoren der Düsseldorfer Studie zu dem Schluß, dasß man die Methode von Huneke in der Behandlung chronischer Rückenschmerzen empfehlen kann. [...].

ARTIKEL ERSCHIENEN AM MO, 25. JULI 2005

DIE ZEIT 


\section{TEXTO 9 \\ GRÜNE FÜR HÖHERE STEUER AUF LUXUSGÜTER \\ Steuerzahlerbund und -gewerkschaft kritisieren Pläne der Union und der Grünen}

Berlin - Die Debatte um die Mehrwertsteuer reißt nicht ab. Während die Grünen einen Extra-Satz für Luxusgüter fordern, regt die Union an, Produkte für Kinder künftig mit dem halben Mehrwertsteuersatz zu belegen. [...] "Produkte, die für Kinder wichtig sind, müssen komplett unter den reduzierten Mehrwertsteuersatz fallen", sagte Böhr der "BILD am Sonntag". "Familien dürfen nicht länger für ihre Kinder bestraft werden." Auch Müller plädierte dafür, den Ermäßigungskatalog neu zu definieren und familienfreundlicher zu gestalten. [...] "Jedem Politiker muß klar sein, daß es keinerlei Experimente geben darf, die sich noch einmal negativ in den Kassen niederschlagen", sagte DSTG-Chef Dieter Ondracek der WELT. [...].

Auch die bereits bekannten Steuerpläne werden von den Steuerexperten scharf kritisiert. Auf Ablehnung stoßen vor allem die geplante Mehrwertsteuererhöhung der Union und die "Reichensteuer" der SPD. "Wir halten eine Mehrwertsteuererhöhung für falsch, weil der Binnenmarkt weiter Schaden nimmt", sagte Ondracek. "Das Umsteuern der Erträge zur Senkung der Lohnnebenkosten ist falsch, weil hier Finanzierungen vermischt werden." Die SPD steht vor allem wegen ihrer Reichensteuer in der Kritik. Für Ondracek ist sie "nur ein Mittel, um Wählerstimmen zu fangen". [...].

\section{$\mathrm{SVB} / \mathrm{CW}$}

\section{ARTIKEL ERSCHIENEN AM MI, 27. JULI 2005}

\section{TEXTO 10}

\section{GUTE FRAGE, SCHLECHTE ANTWORTEN}

Ostdeutschland braucht keinen eigenen Wahlkampf. Aber eine neue politische Sprache. Denn die Rezepte gegen Arbeitslosigkeit, schwächelndes Wachstum und Haushaltskrise gelten für das ganze Land. Sie werden aber unterschiedlich verstanden

Von Karsten Polke-Majewski und Alain-Xavier Wurst

Wählen Ostdeutsche anders als Wessis? Sicher. Sind die Probleme in Ostdeutschland akuter als im Westen? Bestimmt. Braucht es deshalb einen spezifischen Ostwahlkampf? Nein.

Natürlich haben diejenigen Recht, die einen speziellen Wahlkampf für Ostdeutschland für Unsinn halten; jedenfalls, wenn es um die realen Probleme des Landes geht: die hohe Arbeitslosigkeit, die in Mecklenburg ebenso herrscht wie im Ruhrgebiet, die Strukturschwäche mancher Regionen, schwächelndes Wirtschaftswachstum und die Haushaltsnöte von Kommunen und Ländern. Auch ist "Ostdeutschland" längst kein geschlossener Raum mehr, verstehen sich Mecklenburger als Norddeutsche, wollen erfolgreiche Sachsen und Thüringer nicht mit der "kleinen DDR" in Brandenburg in einen Topf geworfen werden. Und überhaupt: Würde irgendjemand einen anderen Wahlkampf für Bremen fordern, weil das Land im Pisa-Test im Vergleich zu Bayern scheiterte?

\section{FRANKFURTER ALLGEMEINE ZEITUNG}

29. Juli, 2005

\section{TEXTO 11}

\section{SCHLEICHENDER ZENTRALISMUS-KÖHLERS REDE}

Von Günter Bannas, Berlin

"Die bestehende föderale Ordnung ist überholt" ist einer der Leitsätze von Bundespräsident Köhler, mit dem er seine Entscheidung argumentativ unterfüttert hat, dem Antrag von Bundeskanzler Schröder zu folgen und den Bundestag aufzulösen. Köhler, der auch in den anderen Passagen seiner Erklärung die Begründungsmuster Schröders übernahm, spielte damit auf dessen Äußerungen im Bundestag über [...]". Neuer Reformversuch

[...] "Als sicher gilt, daß nach dem 18. September ein neuer Versuch zur Reform des Bund-Länder-Verhältnisses unternommen wird".

Umwandlung in Staatendienst

[...] "Das Bund-Länder-Verhältnis ist angespannter geworden, seit sich nach dem Umzug von Regierung und Parlament nach Berlin ein mentaler und sprachlicher Zentralismus breit macht".

\section{FRANKFURTER ALLGEMEINE ZEITUNG}

22. Juli, 2005

\section{TEXTO 12}

\section{GELDWÄSCHEVERDACHT IN DER COMMERZBANK}

Die Commerzbank AG in Frankfurt ist in einen internationalen Geldwäscheskandal verstrickt. Neben Deutschland sind unter anderem die Schweiz, Liechtenstein und Zypern im Visier der Ermittler. 
Die Commerzbank besaß die Holding nur treuhänderisch für die Anleger, wie aus der Bank versichert wird. Für die Zwischenholding Telecom Invest bestanden Börsenpläne, wobei der Commerzbank, wie man hört, ein Beratungsmandat zugesichert war. Dazu ist es allerdings nie gekommen. Die First National Holding wurde Ende 2001 aufgelöst, das Geld soll zum Zweck der weiteren Verschleierung in verschiedene Fonds, unter anderem auf den Bermudas, geflossen sein.

Eine zweite Schaltstelle der Investoren war eine Kapitalanlagegesellschaft in Frankfurt, die zwei Mitarbeiter der Bank nach ihrem Ausscheiden im Jahr 2002 gegründet hatten. Außerdem hatte die Bank im Zuge der Ermittlungen einen Mitarbeiter freigestellt. In das Blickfeld der Behörden soll des weiteren der Repräsentant der Commerzbank in Taschkent geraten sein.

Die „politische Verantwortung"

Der Geldwäsche-Fall wirft auch ein neues Licht auf das Ausscheiden von Vorstandsmitglied Andreas de Maiziere. $[\ldots]$.

\section{"Das kratzt am Ruf"}

Nach Angaben der „Neuen Zürcher Zeitung” haben die Behörden im Wege der Amtshilfe auch Material in Zürich und Zug

F.A.Z. / REUTERS

25. Juli, 2005

\section{TEXTO 13}

\section{IMMER MEHR RENTNER LEBEN IM AUSLAND}

Jeder zehnte Bezieher von Mitteln aus der Gesetzlichen Rentenversicherung (GRV) wohnt im Ausland oder hat während seines Arbeitslebens Ansprüche gegenüber ausländischen Rentenversicherungssystemen erworben. Die Anzahl der sogenannten Vertragsrenten hat sich nach Angaben des Verbands Deutscher Rentenversicherungsträger in den vergangenen 20 Jahren verdreifacht. Dabei gewährleistet das europäische Sozialrecht, das in den 25 Mitgliedstaaten der EU sowie in Norwegen, Liechtenstein, Island und der Schweiz gilt, daß die Ansprüche und Leistungen der jeweiligen sozialen Sicherungssysteme auch grenzüberschreitend gesichert sind.

Anteilige Altersrente

Mit einer Reihe von Staaten, die nicht der EU angehören, hat Deutschland bilaterale Sozialversicherungsabkommen abgeschlossen. Dazu gehören beispielsweise Amerika, Japan oder auch China. Ein Franzose, der in Dänemark, Deutschland und Österreich gearbeitet hat, erhält aus den dänischen, deutschen und österreichischen Rentenkassen anteilig eine Altersrente.

Die Höhe der Rente bestimmt sich nach der Dauer der in den Ländern verbrachten Zeiten. Gleiches gilt auch für einen Japaner, der in die Gesetzliche Rentenversicherung in Deutschland einzahlt. Mit Beginn seiner Altersrente hat er Ansprüche auf Rentenzahlungen aus Deutschland.

Zurïck in die alte Heimat

Von den aktuell 22 Millionen Empfängern von Geld der Gesetzlichen Rentenversicherung leben rund 1,4 Millionen im Ausland; darunter 171.000 Deutsche, die im Ausland ihr Rentnerleben führen. Besonders beliebt sind bei den deutschen Rentnern Österreich und die Schweiz. [...]. Dagegen zieht es einen Großteil der Ausländer nach ihrem Berufsleben in Deutschland wieder zurück in ihre alte Heimat. 80 Prozent von ihnen bekommen ihre Rente in ihr Geburtsland überwiesen: 18 Prozent der vormals in Deutschland Beschäftigten bekommen ihre Rente nach Italien überwiesen, 14 Prozent zog es zurück ins ehemalige Jugoslawien und 12 Prozent in die Türkei.

Es gibt Ausnahmen

Ziel dieser Koordinierung der verschiedenen nationalen Sozialversicherungssysteme ist jedoch nicht, diese auch zu harmonisieren. Es bleibt nach wie vor den Staaten überlassen, wie sie ihre Sozialversicherungssysteme ausgestalten. Dabei ist eine Person immer in dem Land sozialversichert, in dem sie arbeitet [...].

\section{F.A.Z. / REUTERS}

18. Juli 2005

\section{TEXTO 14}

\section{RADIKALPROGRAMM FÜR DEN ARBEITSMARKT}

Die FDP will im Falle eines Wahlsiegs die Arbeitslosenversicherung grundlegend ändern. Der Beitragssatz soll von 6,5 auf 4,5 Prozent gesenkt und die Bundesagentur für Arbeit (BA) abgeschafft und durch ein Drei-SäulenModell ersetzt werden. Das kündigte der Parteivorsitzende Guido Westerwelle am Montag in Berlin bei der Präsentation des Wahlprogramms an (siehe auch: FDP-Vorstand beschließt Wahlprogramm). Die Beitragssenkung, die knapp 15 Milliarden Euro kosten würde, könne vollständig durch eine Neuausrichtung 
der Arbeitsmarktpolitik und strukturelle Änderungen in der BA finanziert werden, betonte Westerwelle; die Mehrwertsteuer brauche dazu nicht erhöht zu werden. Die Liberalen seien damit die einzige Partei, die auf Ausgabenkürzungen und Steuersenkungen setzte. „Das ist das beste Beschäftigungsprogramm.” Werde die BA ganz abgeschafft, seien weitere Effizienzgewinne von 15 Milliarden Euro möglich, erklärten FDP-Generalsekretär Dirk Niebel und der Finanzpolitiker Hermann Otto Solms.

[...] „Bei näherer Betrachtung löst es sich in Nichts auf, wie eine Fata Morgana in der Wüste." So hätten sich die Liberalen nicht nur in der Addition um eine Milliarde Euro verrechnet; sie blieben auch die Antwort schuldig, wie sie die Einnahmeausfälle im Bundeshaushalt finanzieren wollten, die durch die Abschaffung des Aussteuerungsbetrags entstünden. Zudem seien die Verwaltungsausgaben für Arbeitslosengeld-II-Bezieher bereits steuerfinanziert und betrügen nur 3,3 Milliarden Euro. „Nicht einmal durch die völlige Streichung allen Personals im Bereich der Betreuung von Langzeitarbeitslosen könnte man also das von der FDP bezifferte Einsparvolumen rechnerisch erreichen."

In der BA hält man die Pläne ebenfalls für wenig realistisch. Da viele Maßnahmen der aktiven Arbeitsmarktpolitik über mehrere Jahre laufen, schlügen die Einspareffekte selbst bei einem sofortigen Maßnahmestopp erst im Zeitablauf an. So seien zum Beispiel schon 70 Prozent des Vorschusses für den Haushait 2006 gebunden. Außerdem weist die Nürnberger Behörde darauf hin, daß sie bereits viele Unwirtschaftlichkeiten beseitigt und dadurch seit Anfang 2004 mehr als 2 Milliarden Euro gespart habe.

F.A.Z. / REUTERS 25. Juli 2005

\section{CONCLUSIONES}

1) LÉXICO ESPECIALIZADO: - El extenso léxico propio de la jerga y medios de divulgación al ser reiterativo (expresiones sintagmáticas, esquemas oracionales, estilo nominal...) nos facilita la traducción. En los casos de complementación no existe dificultad, si bien los recursos estilísticos pueden presentar rasgos morfoestructurales algo más complejos.

2) POSIBILIDADES PARA EL TRADUCTOR: - El traductor, por su parte, ha de aprovechar los recursos disponibles e información (diccionarios, textos diversos...)

- El traductor debería además de organizar un glosario (expresiones de verbos de acción, terminología, valoración de estructuras sintácticas adaptadas a la LT) y aplicar componentes reiterativos que faciliten la traducción (esquemas complejos que se adecuan y transfieren sin dificultad)

3) CONSECUCIÓN METODOLÓGICA: Conseguiremos así la adaptación de la lengua originaria al texto de destino (TD); de ello se derivará una disminución de las incorrecciones producidas por la DOBLE CODIFICACIÓN de la lengua, es decir, aquellas incorrecciones que el traductor comete cuando analiza determinadas estructuras en su lengua materna y se desprende del sistema lógico de la segunda lengua.

4) OBJETIVOS: Nuestro objetivo siempre debe ser la consecución de una traducción transparente, clara y eficaz . 


\section{REFERENCIAS BIBLIOGRÁFICAS}

ALBRECHT, J., Linguistik und Übersetzung, Tubinga, Niemeyer, 1993.

ARNTZ, R./ THOME, G., Übersetzungswissenschaft. Ergebnisse und Perspektiven. Festschrift für W. Wilss zum 65. Geburtstag, Tubinga, Narr, 1990.

AUSTIN, J.L., How to do things with words, Oxford, OUP, 1996.

BAKER, M., In Other Words. A Coursebook on Translation, London, Routledge, 1992.

BALLARD, M., La traduction: de la théorie à la didactique, Lille, Presses Universitaires, 1996.

BENITO, Á., Lecciones de Teoría General de la Información II. La comunicación social, Madrid, FCE, 1995.

- Teoría de la Información, Madrid, Comunica Press, 2002.

BERNABEU MORÁN, N., “Cómo realizar el análisis crítico de una noticia en las aulas? Comentario de un texto periodístico", Comunica, 3, 1994, pp. 108-113.

BUCHER, H.J., Pressekommunikation. Grundstrukturen einer öffentlichen Form der Kommunikation aus linguistischer Sicht, Tubinga, Niemeyer, 1986.

CASTRO MORENO, C., "Supuestos teórico-prácticos de morfología alemana", AGA (eds.), Magazin, Sevilla, 2003, pp. 70-71.

- "Problemas traductológicos en el ámbito de las estructuras hipotácticas abreviadas a través de participio y gerundio", Estudios Filológicos Alemanes, vol. 9, Sevilla, Kronos, 2004, pp. 243-258.

CHARLO BREA, L., Reflexiones sobre la traducción, Cádiz, Universidad de Cádiz, 1995.

CLEMENTE, J. C., Lenguas y medios de comunicación, Madrid, Publ. Fundación Actilibre, 1992.

DEL RÍO REYNAGA, J., Teoría y práctica de los géneros periodísticos informativos, México, Diana, 2001.

DELISLE, J., La Traduction Raisonée, Canadá, Universidad de Ottawa, 1993.

DOLLERUP, C. y LINDEGAARD, A. (eds.), Teaching Translation and Interpreting, Amsterdam, John Benjamins Publishing, 2004.

DOVIFAT, E., Periodismo: Fundamentos teóricos y jurídicos, noticia y opinión, lenguaje y forma de expresión, México, Uteha, 1999.

ECO, U. "Para una indagación semiológica sobre el mensaje televisivo", AAVV, Los efectos de las comunicaciones de masas, 1969, Buenos Aires, Jorge Álvarez, pp. 133.

ELENA GARCÍA, P., Aspectos teóricos y prácticos de la traducción (alemán-español), $1^{\mathrm{a}}$ reimpr., Salamanca, Universidad de Salamanca, 1994.

FAUS BELAU, Á., La Radio: introducción a un medio desconocido, $2^{\mathrm{a}}$ ed., Madrid, Guadarrama, 2004.

FUENTES, J. F./ FERNÁNDEZ SEBASTIÁN, J., Historia del periodismo español, Madrid, Sintesis, 1997.

GARCÍA GONZÁlEZ, A./ ROMÁN PORTAS, M. "Panorama de la audiencia radiofónica", Comunica (Revista electrónica: http://wwwaijic.com/comunica.htm), vol. 3., 2002.

- "Textsorten in der Regionalpresse. Bemerkungen zu ihrer Gestaltung und Entwicklung", Sprache-System und Tätigkeit, vol. 25, Francfort del Main, Peter Lang, 1998. 
GARCÍA YEBRA, V., Teoría y práctica de la traducción, Madrid, Gredos, 1982.

- En torno a la traducción. Teoría. Crítica. Historia, Madrid, Gredos, 1983.

GUTIÉRREZ PAlACIO, J., Periodismo de opinión, Madrid, Paraninfo, 1994.

HERVEY, S.; HIGGINS, I. y HAYWOOD L. M., Thinking Spanish Translation, Londres, Routledge, 1992.

-/ Thinking translation: a course in translation method, French-English, Londres, Routledge, 1995.

HICKEY, L. y VÁZQUEZ ORTA, I., "Sustantivo - presuposición - sustantivo: ¿secuencia admisible o inadmisible en castellano?", ACIS, vol. 7, 1, 1994, pp. 27-37.

HOLMES, J. "The name and nature of translation", J. Holmes (eds.), Papers in literary translation and translation studies, Amsterdam, Rodopi, 1998, 66-80.

HURTADO, A., "La traduction: Classification et éléments d'analyse", Meta, 41/1, 1996.

—l'La didáctica de la traducción. Evolución y estado actual", Fernández, P. y Bravo, J. M. (eds.), Perspectivas de la traducción, Valladolid, Universidad de Valladolid, 1995, 4974.

HÖNIG, H. G., Konstruktives Übersetzen, Tubinga, Stauffenburg, 1997.

- KUSSMAUL, P., Strategie der Übersetzung. Ein Lehr- und Arbeitsbuch, Tubinga, Narr, 1999.

JAKOBSON, R. "On Linguistic Aspects of Translation", Reuben A. Brower (eds.), On Translation, Nueva York, Oxford, 1959, 232-239.

KOLLER, W. Einführung in die Übersetzungswissenschaft, Heidelberg, Quelle \&Meyer, 1983.

KOSYK K./ PRUYS, K. H. (eds), Handbuch der Massenkommunikation, Múnich, dtv, 1981.

KÜBLER, H. D. "Kommunikation und Massenkommunikation. Ein Studienbuch", Medien \& Kommunikation, vol. 21, Hamburgo, Münster, 1994.

LATORRE-PALLARES, M. ET AL. Übersetzung Deutsch-Spanisch. Zwölf Texte mit kommentierter Übersetzung, Saarbrücken, Universitas Saraviensis, 1995.

LÁZARO CARRETER, F., El lenguaje periodístico, entre el literario, el administrativo y el vulgar. El lenguaje en periodismo escrito, Madrid, Fundación Juan March, 1987.

LE BEL, E., Le masque et la plume. Traducir: Reflexiones, experiencias y prácticas, Sevilla, Universidad de Sevilla, 1995.

LEECH, G. N. y SHORT, M. H., Style in Fiction. A Linguistic Introduction to English Fictional Prose, Nueva York, Longman, 2001.

LÓPEZ GARCÍA, Á., Escritura e información. La estructura del lenguaje periodístico, Madrid, Cátedra, 1996.

LÜGER, H. H., Pressesprache, Tubinga, Niemeyer, 1995.

MARTIN, A., "La formación del traductor: la interpretación", Nouvelles de la F.I.T., Nouvelle Série, XII, núm. 1-2, 1993, pp. 24-28.

MARTÍN VIVALDI, G., Géneros periodísticos, Madrid, Paraninfo, 2003, pp. 10.

MARTÍNEZ ALBERTOS, J. L., El lenguaje periodístico, Madrid, Paraninfo, 1998.

MASON, I. "Techniques of translation revisited: a text linguistic review of borrowing and modulation", A. Hurtado (eds.), Estudis sobre la Traducció, Castellón, Universitat Jaume I, 1994, pp. 61-72. 
MAST, C., ABC des Journalismus. Ein Leitfaden für die Redaktionsarbeit, Constanza, UVK Medien, 1998.

MEDINA REGUERA, A., El léxico periodístico alemán, Sevilla, Bienza, 2004.

MEYN, H., "Massenmedien in der Bundesrepublik Deutschland", Zur Politik und Zeitgeschichte, vol. 24, Berlín, Colloquium, 1996, pp. 50-51.

MORENO ESPINOSA, P., "Curso de redacción periodística en prensa, radio y televisión", Sevilla, Mad, 1998.

MUÑOZ, J. J., Redacción periodística. Teoría y práctica, Salamanca, Librería Cervantes, 1994.

MUÑOZ MARTÍN, R., Lingüística para traducir, Barcelona, Teide, 1995.

NEUBERT, A., Text and translation, Leipzig, Enzyklopaëdie, 1995.

NIDA, E. A./ TABER, CH. R., La traducción: Teoría y práctica, Madrid, Cristiandad, 1986.

NORD, CH., Textanalyse und Übersetzen, $2^{\text {a }}$ ed., Heidelberg, J. Groos, 1991.

PALACIOS, M, Historia de la televisión en España, Barcelona, Gedisa, 2001.

PEÑA, S./ HERNÁNDEZ GUERRERO, Mª J., Traductología, Universidad de Málaga, Málaga, 1994.

PÉREZ CALDERÓN, M., La información audiovisual, Madrid, Akal, 2000.

PÖCHHACKER, F., "The role of theory in simultaneous interpreting", C. Dollerup y A. Loddegaard, (eds), Teaching Translation and Interpreting: Training, Talent and Experience, Amsterdam, John Benjamins, 1992, pp. 211-220.

— "Those Who Do...: A Profile of Research(ers) in Interpreting", Target, 1995, pp. 47-64.

PRADO, E. Estructura de la información radiofónica, $3^{\mathrm{a} e d ., ~ B a r c e l o n a, ~ M i t r e, ~} 2001$.

PROSS, H., Zeitungsreport. Deutsche Presse im 20. Jahrhundert, Weimar, 1999.

- ROMANO, V., Atrapados en la red mediática. Orientación en la diversidad, Hondarribia, Argitaletxe Hiru, 2000.

REIß, K./ VERMEER, H., Grundlegung einer allgemeinen Translationstheorie, Tubinga, Niemeyer, 1991.

ROLOFF, E. K., Journalistische Textgattungen, Múnich, 1982.

ROMERO GUALDA, M. V., El español en los medios de comunicación, Madrid, Arco Libros, 2003.

ROSSELl IBERN, A. M., Manual de traducción: Alemán / Castellano, Barcelona, Gedisa, 1996.

SÁEZ HERMOSILLA, T., El sentido de la traducción: reflexión y crítica, León/Salamanca, Secretariado de Publicaciones, 1994.

SAGER, J. C. Language Engineering and Translation. Consequences of automation, Amsterdam, Benjamins, 1993.

SAN GINÁS AGUILAR, P., "Traducción: teórica y práctica", Sendebar, vol. 1, 1990, pp. 65-70.

SANTOS, J., Madrid, historia de una capital, Madrid, Alianza, 1995, pp. 348-349.

SCHNEIDER, W., Deutsch für Profis. Wege zu gutem Stil, Goldmann, München, 1991.

-/ RAUE, P. J. Handbuch des Journalismus, Rowohlt, Reinbeck, Hamburg, 1996.

SNELL-HORNBY, M., Translation Studies. An integrated approach, Amsterdam, John Benjamins, 1998. 
STOLZE, R., Übersetzungstheorien. Eine Einführung, $2^{a}$ ed., Tubinga, Narr, 1997.

URABAYEN, M., Estructura de la información periodística. Concepto y método, Barcelona, Mitre, 1998.

VAN DAM, I., "Strategies of Simultaneous Interpretation", L. Gran y J. Dodds (eds.) The Theoretical and Practical Aspects of Teaching Conference Interpretation, Udine, Campanotto, 1989, pp. 167-176.

VÁZQUEZ-AYORA, G., Introducción a la Traductología, Washington, Georgetown University Press, 1997.

VERÓN, E., "Ideología y comunicación de masas: la semantización de la violencia política", Lenguaje y comunicación, Buenos Aires, Nueva Visión, 1999, pp. 30-34.

VIDAL CLARAMONTE, $\mathrm{M}^{\mathrm{a}}$ C. A. Traducción, manipulación, desconstrucción, Salamanca, Colegio de España, 1995.

WILSS, W. Übersetzungswissenschaft. Probleme und Methoden, $3^{\mathrm{a}}$ ed., Stuttgart, Klett, 2000.

- Kognition und Übersetzen. Zur Theorie und Praxis der menschlichen und der maschinellen Übersetzung, Tubinga, Niemeyer, 2001.

- Steps to Consecutive Interpretation, Nueva York, Pen \& Booth, 2004.

- THOME, G. Translation Theory and its Implementation in the Teaching of Translating and Interpreting, Tubinga, Gunter Narr, 1994.

WRIGHT, S. E. y WRIGHT, L. D., Scientific and technical translation, Amsterdam, John Benjamins, 2003.

ZABALBEASCOA, P., "Aplicaciones de la traducción a la enseñanza de lenguas extranjeras”, J. Tió (eds.) Sintagma, vol. 2, Lleida, Estudi General de Lleida, 1992.

-l'Un esquema de prioridades y restricciones para la didáctica de la traducción", I Jornadas Internacionales de Traducción e Interpretación, Gran Canaria, Universidad de Las Palmas de Gran Canaria, 1994. 